\title{
ESTIMASI KORELASI GENETIK BERAT LAHIR DAN BERAT SAPIH PADA DOMBA EKOR GEMUK DI UPT PT-HMT GARAHAN, JEMBER, JAWA TIMUR
}

\section{ESTIMATION OF GENETIC CORRELATION BETWEEN BIRTH AND WEANING WEIGHT OF FAT TALLED SHEEP AT UPT PT-HMT GARAHAN, JEMBER, EAST JAVA}

\author{
Sumadi*, Muflikhun, dan I Gede Suparta Budisatria \\ Fakultas Peternakan, Universitas Gadjah Mada, J. Fauna No. 3, Bulaksumur, Yogyakarta, 55281
}

\section{INTISARI}

Penelitian ini dilakukan untuk mengestimasi nilai korelasi genetik antara berat lahir dengan berat sapih pada domba Ekor Gemuk di Unit Pelaksana Teknis Pembibitan Ternak dan Hijauan Makanan Ternak (UPT PT-HMT) Garahan, Jember, Jawa Timur. Penelitian ini menggunakan catatan data yang berupa data berat lahir dan data berat sapih dari 18 ekor pejantan dengan jumlah keturunan 120 ekor cempe. Data penunjang lainnya adalah data silsilah, perkawinan, tipe kelahiran, tanggal lahir, tanggal sapih, dan penimbangan berat badan yang tersedia sejak tahun 2006 sampai 2011. Metode statistik yang digunakan untuk mengestimasi korelasi genetik adalah berdasarkan hubungan saudara tiri sebapak, yang dianalisis dengan metode One Way Analysis of Variance. Hasil penelitian menunjukkan bahwa nilai estimasi korelasi genetik antara berat lahir dengan berat sapih sebesar $0,82 \pm 0,06$. Berdasarkan hasil penelitian ini dapat disimpulkan bahwa nilai korelasi genetik antara berat lahir dengan berat sapih termasuk positif tinggi.

(Kata kunci: Domba Ekor Gemuk, Berat lahir, Berat sapih, Korelasi genetik)

\section{ABSTRACT}

The experiment was conducted to estimate the value of genetic correlations between birth weight and weaning weight of fat tailed sheep at the Unit Pelaksana Teknis Pembibitan Ternak dan Hijauan Makanan Ternak (UPT PTHMT) Garahan, Jember, East Java. The research was conducted based on recording data of birth and weaning weight from 18 bucks with 120 lambs. Other supporting data were pedigree, mating, birth type, birth date, weaning and body weight which recorded from 2006 to 2011. The statistical method used to estimate the genetic correlation based on the method of halfsibs. Results showed that the estimated value of the genetic correlation between weaning weight and birth weight was $0.82 \pm 0.06$. In conclusion, value of the genetic correlation between weaning weight and birth weight was estimated in highly positive.

(Keywords: Fat Tailed sheep, Birth weight, Weaning weight, Genetic correlation)

\section{Pendahuluan}

Kesadaran dan pengertian masyarakat tentang arti pentingnya gizi akan meningkat, sejalan dengan semakin meningkatnya taraf hidup suatu masyarakat. Hal tersebut dapat dilihat dari meningkatnya kebutuhan daging sebesar $2,7 \%$ per tahun (Mulyanto dan Sarwono, 2004). Sementara itu, persediaan daging di pasar hanya dicukupi dengan daging sapi. Oleh karena itu, diperlukan daging ternak lain khususnya daging domba. Daging domba mampu memberikan sumbangan sebesar 6,6\% dari konsumsi daging secara keseluruhan (Sodiq dan Abidin, 2002).

Domba merupakan ternak ruminansia kecil yang banyak dipelihara di Indonesia dalam skala usaha kecil di daerah pedesaan. Produksi ternak ruminansia kecil termasuk domba, memegang peranan penting di daerah tropis yaitu sebagai sumber pendapatan, terutama bagi buruh tani yang tidak mempunyai lahan, sebagai tabungan untuk pengeluaran mendadak, sebagai sumber pupuk kandang disamping memegang peranan penting dalam kehidupan sosial di desa.

Di Indonesia, 99\% ternak domba berada di tangan peternak rakyat dengan pola pemeliharaan tradisional. Peluang pasar domba yang masih terbuka lebar tersebut menjadi tantangan bagi peternak rakyat, karena sebagian besar populasi domba berada di tangan peternak rakyat. Tantangan tersebut perlu dijawab dengan menghasilkan ternak domba dengan kuantitas dan kualitas yang baik, dengan mengoptimalkan segala sumber daya yang tersedia. Ternak domba menyebar rata di seluruh wilayah nusantara, hal ini menunjukkan bahwa domba mempunyai potensi cepat menyesuaikan diri

\footnotetext{
* Korespondensi (corresponding author):

Telp. +6281328832260

Email: profsumadi@yahoo.co.id
} 
baik dengan lingkungan maupun kultur masyarakat Indonesia. Oleh karena itu ternak domba perlu ditingkatkan produktivitasnya melalui perbaikan mutu genetik.

Salah satu cara perbaikan mutu genetik ternak dapat dilakukan melalui seleksi dan pengaturan perkawinan. Seleksi dilakukan terhadap sifat fenotip ternak yang mempunyai nilai ekonomi tinggi. Pada ternak potong umumnya dilakukan dengan memilih ternak yang mempunyai berat badan tinggi dalam populasi. Peternak mengharapkan dengan bibit yang berat badannya tinggi akan diperoleh keturunan dengan berat badan tinggi pula. Pelaksanaan program perbaikan mutu genetik pada ternak, selalu dilakukan pada sifat-sifat yang mempunyai nilai ekonomi tinggi antara lain berat sapih, berat satu tahun, pertumbuhan sebelum disapih, dan pertumbuhan setelah disapih (Lasley, 1978).

Produktivitas ternak dipengaruhi oleh faktor genetik dan faktor lingkungan, di mana ternak berada atau merupakan interaksi dari keduanya. Ada beberapa cara untuk meningkatkan produksi ternak khususnya domba Ekor Gemuk (DEG) yaitu perbaikan mutu pakan ternak, perbaikan tata laksana dan peningkatan mutu genetiknya. Potensi genetik yang dimiliki masing-masing individu diturunkan kepada generasi berikutnya dan besarnya variasi yang berakibat menurun dapat diduga dengan parameter genetiknya. Parameter genetik terdiri atas heritabilitas, repitabilitas, dan korelasi genetik pada suatu sifat tertentu.

Pengetahuan tentang parameter genetik sangat dibutuhkan dalam pelaksanaan seleksi pada pemuliaan ternak untuk dapat meningkatkan mutu genetik. Salah satu parameter genetik yaitu korelasi genetik yang bermanfaat untuk menduga besarnya perubahan pada sifat lain yang berkorelasi terhadap suatu sifat apabila dilakukan seleksi terhadap suatu sifat tersebut. Nilai korelasi genetik mencerminkan keragaman genetik antara sifat-sifat yang berkorelasi pada suatu populasi dan bukan suatu konstanta karena selalu mengalami perubahan.

Menurut Warwick et al. (1990), nilai korelasi genetik berat lahir dan berat sapih pada DEG adalah $+0,25$ sampai $+0,5$. Korelasi genetik digunakan untuk melihat sejauhmana hubungan antara berat lahir dan berat sapih pada DEG, sehingga dapat digunakan sebagai salah satu kriteria seleksi tidak hanya digunakan pada sebuah peternakan besar tetapi juga pada peternakan rakyat.

Seleksi dan introduksi darah baru yang dilakukan terhadap suatu populasi ternak akan mengubah frekuensi gen tertentu yang berakibat pada berubahnya nilai korelasi genetik. Oleh karena itu nilai korelasi genetik harus diestimasi kembali secara periodik agar menjadi pedoman yang akurat untuk merancang, menyusun, dan mengevaluasi program pemuliaan dalam suatu populasi. Metode korelasi genetik ini diharapkan mampu digunakan sebagai kriteria seleksi bagi ternak-ternak yang memiliki produktivtas tinggi, melalui seleksi korelasi genetik berat lahir dan berat sapih.

Salah satu unit pelaksana teknis pembibitan ternak DEG adalah Unit Pelaksana Teknis Pembibitan Ternak dan Hijauan Makanan Ternak (UPT PT-HMT) Garahan, Jember, Jawa Timur yang tercatat sebagai sumber bibit DEG. Sebagai sumber bibit, UPT PT-HMT Garahan selalu melakukan seleksi untuk meningkatakan mutu genetik DEG. Berdasarkan uraian di atas maka dilakukan penelitian mengenai estimasi korelasi genetik berat lahir dan berat sapih pada domba Ekor Gemuk di UPT PT-HMT, Garahan, Jember, Jawa Timur yang diharapkan dapat dijadikan informasi untuk dasar melakukan seleksi yang baik terhadap DEG.

\section{Materi dan Metode}

Penelitian dilaksanakan di UPT PT-HMT, Garahan, Jember, Jawa Timur. Materi penelitian adalah data DEG di UPT PT-HMT Garahan, Jember, Jawa Timur. Data yang dikumpulkan meliputi data berat lahir dan data berat sapih lima tahun terakhir dari 120 ekor keturunan yang berasal dari 18 ekor pejantan. Data penunjang lainnya adalah data silsilah, perkawinan, tipe kelahiran, tanggal lahir, tanggal sapih, dan penimbangan berat badan.

Metode yang digunakan dalam penelitian adalah studi kasus di UPT PT - HMT, Garahan, Jember, Jawa Timur. Data diperoleh dari recording yang ada di UPT PT-HMT Garahan, Jember, Jawa Timur.

\section{Analisis data}

Data yang diperoleh ditabulasi berdasarkan tetua pejantannya. Data berat lahir dikoreksi terhadap jenis kelamin, umur induk, dan tipe kelahiran. Koreksi terhadap jenis kelamin dilakukan dengan cara rata-rata berat lahir cempe jantan dibagi dengan rata-rata berat lahir cempe betina. Hasil tersebut digunakan untuk mengalikan individu betina. Anak jantan menggunakan berat lahir asal (Sulastri, 2001).

Koreksi terhadap umur induk dilakukan dengan cara apabila umur induk pada waktu melahirkan berturut-turut adalah $1,2,3,4$, dan 5 tahun maka berat anak berturut-turut dikalikan dengan 1,$21 ; 1,10 ; 1,05 ; 1,03 ;$ dan 1,00 . Faktor koreksi untuk tipe kelahiran adalah berat lahir cempe dikalikan 1,15 untuk kelahiran kembar dan sistem pemeliharaan kembar, 1,10 untuk kelahiran kembar dengan sistem pemeliharaan tunggal dan 1,00 untuk kelahiran tunggal (Hardjosubroto, 1994). 
Berat sapih dikoreksi terhadap jenis kelamin seperti pada berat lahir dan terhadap umur sapih 90 hari. Menurut Sulastri (2001) rumus yang digunakan untuk penyesuaian adalah sebagai berikut:

Berat lahir dikoreksi terhadap jenis kelamin, umur induk dan tipe kelahiran.

\section{$\mathrm{BLT}=\mathrm{BLN} \times \mathrm{FKJK} \times$ FKTL $\times$ FKUI}

Berat sapih dikoreksi ke rata-rata umur sapih, jenis kelamin, tipe kelahiran dan umur induk.

$$
\mathrm{BST}=(\mathrm{BLN}+\underset{\text { umur }}{\mathrm{BSN}-\mathrm{BLN}} \times \text { 90) FKJK } \times \text { FKUI } \times \text { FKTL }
$$

\section{Keterangan:}

BLT = berat lahir terkoreksi

BLN = berat lahir nyata

FKJK = faktor koreksi jenis kelamin

FKUI = faktor koreksi umur induk

FKTL = faktor koreksi tipe kelahiran

BST = berat sapih terkoreksi

BSN = berat sapih nyata

Umur = umur anak domba saat disapih

Metode statistik yang digunakan untuk mengestimasi korelasi genetik adalah berdasarkan hubungan saudara tiri sebapak, yang dianalisis dengan metode One Way of Variance sesuai petunjuk Becker (1992).

Nilai korelasi genetik dihitung dengan rumus sebagai berikut:

$$
\mathbf{r}_{\mathrm{G}}=\frac{4 \operatorname{covs}}{\sqrt{4 \sigma_{\mathrm{g}(\mathrm{x})}^{2} 4 \sigma_{\mathrm{s}(\mathrm{y})}^{2}}}
$$

Tabel 1. Analisis ragam korelasi genetik dengan menggunakan data saudara tiri sebapak (variance analysis of genetic correlation using halfsib data)

\begin{tabular}{lcccc}
\hline \multicolumn{1}{c}{ Sumber (source) } & $\mathrm{df}$ & $\mathrm{SCP}$ & $\mathrm{MCP}$ & $\mathrm{EMCP}$ \\
\hline Pejantan (sire) & $\mathrm{S}-1$ & $\mathrm{SCP}_{\mathrm{s}}$ & $\mathrm{MCP}_{\mathrm{s}}$ & $\mathbf{C o v}_{\mathrm{w}}+\mathbf{k c o v}_{\mathrm{s}}$ \\
Anak dalam pejantan (offspring within sire) & $\mathrm{n} . \mathrm{-S}$ & $\mathrm{SCP}_{\mathrm{w}}$ & $\mathbf{M C P}_{\mathrm{w}}$ & $\operatorname{Cov}_{\mathrm{w}}$ \\
\hline
\end{tabular}

$\mathrm{df}=$ derajat bebas (degree of freedom), $\mathrm{S}=$ jumlah pejantan (number of sire), $\mathrm{n} .=$ jumlah seluruh anak (number of progenies), $\mathrm{k}=$ jumlah anak tiap pejantan (number of progeny per sire), $\mathrm{SCP}=$ jumlah hasil kali (sum of cross product), MCP = hasil kali rata-rata (mean of cross product), EMS = hasil kali rata-rata harapan (expected mean squares).

\section{Keterangan:}

Faktor koreksi $(\mathrm{FK})=\frac{\mathrm{X} . . \mathrm{Y}_{\text {.. }}}{\mathrm{n.}}$

$\mathrm{SCP}_{\mathrm{s}}=\sum_{\mathrm{i}} \frac{\mathrm{Xi} . \mathrm{Yi}}{\mathrm{ni}}-\mathrm{FK}$

$\mathrm{SCP}_{\mathrm{w}}=\sum_{\mathrm{i}} \sum_{\mathrm{k}} \mathrm{Xik} Y i k-\sum_{\mathrm{i}} \frac{\mathrm{Xi.Yi}}{\mathrm{ni}}$

$\mathrm{MCP}_{\mathrm{s}}=\mathrm{SCP}_{\mathrm{g}} /(\mathrm{S}-1)$
Nilai $\sigma_{S(x)}^{2}$ dan $\sigma_{S(y)}^{2}$ dihitung sebagaimana pada heritabilitas masing-masing sifat (Becker, 1992) sebagaimana Tabel 2 .

Nilai $\sigma_{s}^{2}$ dihitung dari persamaan:

$$
\begin{aligned}
& \sigma_{\mathrm{w}}^{2}=\mathrm{MS}_{\mathrm{w}} \\
& \sigma_{\mathrm{s}}^{2}=\left(\mathrm{MS}_{\mathrm{s}}-\mathrm{MS}_{\mathrm{w}}\right) / \mathrm{k} \\
& \mathrm{k}=\frac{1}{s-1} \times\left(n \cdot-\frac{\sum x y}{n .}\right)
\end{aligned}
$$

Salah baku korelasi genetik dihitung menggunakan rumus (Warwick et al., 1990).

$$
\operatorname{SE}\left(r_{\mathrm{gxy}}^{2}\right)=\frac{1-r_{\mathrm{gxy}}^{2}}{\sqrt{2}} \times \sqrt{\frac{\sigma h^{2} \mathrm{x} \times \sigma h^{2} y}{h^{2} \times h^{2} y}}
$$

Keterangan:

$$
\begin{array}{ll}
\mathrm{r}_{\mathrm{gxy}} & =\text { korelasi genetik } \\
\sigma \mathrm{h}^{2} \mathrm{x} & =\text { standard error heritabilitas sifat pertama } \\
\sigma \mathrm{h}^{2} \mathrm{y} & =\text { standard error heritabilitas sifat kedua } \\
\mathrm{h}^{2} \mathrm{x} & =\text { heritabilitas sifat pertama } \\
\mathrm{h}_{\mathrm{y}}^{2} & =\text { heritabilitas sifat kedua }
\end{array}
$$

\section{Hasil dan Pembahasan}

\section{Berat lahir}

Pada Tabel 3 menunjukkan bahwa berat lahir dan berat sapih terkoreksi pada DEG masingmasing sebesar $2,45 \pm 0,58 \mathrm{~kg}$ dan $9,80 \pm 1,61 \mathrm{~kg}$. Berat lahir yang diperoleh pada penelitian ini lebih besar dibandingkan dengan hasil penelitian Prabawa (2003) di tempat yang sama yaitu $2,10 \mathrm{~kg}$ dan hasil penelitian Triwulaningsih (1986), rata-rata berat lahir pada DEG dari litter size 1, 2, dan 3 masingmasing $3 \mathrm{~kg}, 2,5 \mathrm{~kg}$, dan $2,2 \mathrm{~kg}$. Perbedaan 
Tabel 2. Analisis ragam dan pemisahan komponen ragam estimasi heritabilitas (variance analysis and component separation of the variance heritability estimation)

\begin{tabular}{|c|c|c|c|c|}
\hline Sumber (source) & df & SS & MS & EMS \\
\hline $\begin{array}{l}\text { Pejantan (sire) } \\
\text { Anak dalam pejantan (offspring within sire) }\end{array}$ & $\begin{array}{r}\mathrm{S}-1 \\
\mathrm{n} .-\mathrm{S} \\
\end{array}$ & $\begin{array}{l}\mathrm{SS}_{\mathrm{s}} \\
\mathrm{SS}_{\mathrm{w}}\end{array}$ & $\begin{array}{l}\mathrm{MS}_{\mathrm{s}} \\
\mathrm{MS}_{\mathrm{w}}\end{array}$ & $\begin{array}{c}\sigma_{w}^{2}+k \sigma_{s}^{2} \\
\sigma_{w}^{2}\end{array}$ \\
\hline
\end{tabular}

$\mathrm{df}=$ derajat bebas (degree of freedom), $\mathrm{S}=$ jumlah pejantan (number of sire), $\mathrm{n} .=$ jumlah seluruh anak (number of progenies), $\mathbf{k}=$ jumlah anak tiap pejantan (number of progeny per sire), $\mathbf{S S}=$ jumlah kuadrat (sum of square), MS = kuadrat tengah (mean of square), EMS = kuadrat tengah harapan (expected mean square).

\section{Keterangan:}

Faktor koreksi $(\mathrm{FK})=\frac{\mathrm{Y}^{2}}{\mathrm{n}}$ $\mathrm{SS}_{\mathrm{s}}=\sum_{\mathrm{i}} \frac{\mathrm{Y}^{\mathbf{2}_{\mathbf{i}}}}{\mathrm{n}_{\mathbf{i}}}-\mathrm{FK}$

$$
\begin{aligned}
& \mathrm{SS}_{\mathrm{w}}=\sum_{\mathrm{i}} \sum_{\mathrm{k}} \mathrm{Y}_{\mathrm{ik}}^{2}-\sum_{\mathrm{i}} \frac{\mathrm{Y}^{2}}{\mathrm{n} .} \\
& \mathrm{MS}_{\mathrm{s}}=\mathrm{SS}_{\mathrm{s}} /(\mathrm{S}-1) \\
& \mathrm{MS}_{\mathrm{w}}=\mathrm{SS}_{\mathrm{w}} /(\mathrm{n} .-\mathrm{S})
\end{aligned}
$$

Tabel 3. Rerata berat lahir dan berat sapih pada DEG (average birth and weaning weight of fat tailed sheep)

\begin{tabular}{lcc}
\hline \multicolumn{1}{c}{ Sifat (trait) } & $\begin{array}{c}\text { Berat nyata } \pm \mathrm{SD}(\mathrm{kg}) \text { (real } \\
\text { weight } \pm S D(\mathrm{~kg}))\end{array}$ & $\begin{array}{c}\text { Berat terkoreksi } \pm \text { SD (kg) (corrected } \\
\text { weight } \pm S D(\mathrm{~kg}))\end{array}$ \\
\hline Berat lahir (birth weight) & $2,40 \pm 0,57$ & $2,45 \pm 0,58$ \\
Berat sapih (weaning weight) & $9,95 \pm 1,65$ & $9,80 \pm 1,61$ \\
\hline
\end{tabular}
$\mathrm{SD}=$ standar deviasi (deviation standard).

ini dapat terjadi karena bangsa ternak yang digunakan berbeda, populasi berbeda, dan kondisi lingkungan yang berbeda.

Domba yang digunakan dalam penelitian ini adalah bangsa DEG, sehingga berat lahir yang dimiliki lebih besar dibandingkan dengan referensi. Menurut Hafez (1980), perbedaan bangsa memberikan keragaman dalam kecepatan pertumbuhan dan komposisi tubuh.

Perbedaan jumlah populasi yang digunakan dalam penelitian juga mempengaruhi perbedaan hasil. Hal ini dikarenakan jumlah ternak yang digunakan dalam setiap penelitian berbeda-beda. Semakin banyak populasi maka semakin diperoleh hasil rata-rata yang seragam. Kondisi lingkungan yang berbeda juga mempengaruhi perbedaan berat lahir yaitu keadaan iklim di tempat satu dengan yang lain berbeda.

\section{Berat sapih}

Berat sapih yang diperoleh pada penelitian ini yaitu 9,80 $\pm 1,61 \mathrm{~kg}$ (Tabel 3) berbeda dibandingkan dengan hasil penelitian Prabawa (2003) di tempat yang sama yaitu $8,35 \mathrm{~kg}$ dan juga berbeda dengan hasil penelitian Triwulaningsih (1986), rata-rata berat sapih pada DEG dengar litter size 1, 2, dan 3 masing-masing $10,5 \mathrm{~kg}, 10 \mathrm{~kg}$, dan $9,8 \mathrm{~kg}$. Perbedaan ini dapat terjadi disebabkan oleh bangsa ternak yang digunakan berbeda, jumlah populasi yang berbeda, dan kondisi lingkungan yang berbeda.
Perbedaan bangsa memberikan keragaman dalam kecepatan pertumbuhan dan komposisi tubuh. Ternak dari bangsa tertentu cenderung tumbuh dan berkembang dalam suatu sifat khas dan menghasilkan karkas dengan sifat tersendiri, sehingga merupakan sifat khas bangsanya. Perbedaan laju pertumbuhan di antara bangsa dan individu ternak, disebabkan oleh perbedaan ukuran tubuh dewasa. Bangsa ternak yang besar mempunyai berat lahir yang lebih berat, tumbuh lebih cepat dan lebih berat pada saat mencapai kedewasaan dari pada bangsa ternak yang kecil (Hafez, 1980).

Berat sapih merupakan indikator dari kemampuan induk untuk menghasilkan susu dan kemampuan anak untuk mendapatkan air susu dan tumbuh (Hardjosubroto, 1994). Subandriyo (1996) menyatakan bahwa berat anak saat disapih dipengaruhi oleh tipe kelahirannya. Hal ini dikarenakan terbatasnya produksi susu induk, sehingga apabila induk mempunyai anak kembar maka jumlah susu yang terbatas tersebut harus dibagi-bagi.

Banyak faktor yang berpengaruh terhadap berat sapih, namun pertumbuhan sebelum sapih lebih didominasi oleh faktor nutrisi yang sepenuhnya berasal dari air susu induk. Hal ini berarti induk yang memiliki produksi susu tinggi, maka anaknya cenderung akan memiliki pertumbuhan yang lebih baik. Produksi susu induk dipengaruhi oleh umur dan pakan yang diberikan (Basuki et al., 1998). 
Jumlah dan kualitas susu induk dipengaruhi oleh jumlah dan kualitas pakannya. Genetik induk dan pejantan akan diturunkan kepada anaknya. Namun demikian, anak yang dihasilkan dari perkawinan induk dan pejantan yang baik akan mempunyai kinerja yang baik seperti tetuanya meskipun pemeliharaannya pada lingkungan yang tidak sama. Kualitas induk dan litter size berkaitan erat dengan kompetisi anak dalam mendapatkan nutrisi dari induknya, baik sebelum lahir maupun prasapih.

\section{Korelasi genetik}

Korelasi genetik merupakan korelasi antara nilai pemuliaan aditif pada dua sifat ternak atau merupakan pengaruh gen-gen aditif terhadap dua sifat atau lebih. Korelasi genetik disebabkan oleh aksi gen pleotropik yaitu gen-gen yang mempengaruhi dua sifat atau lebih (Warwick et al., 1990).

Korelasi genetik berat lahir dengan berat sapih diestimasi berdasarkan hubungan saudara tiri sebapak dan hasilnya sebesar 0,82 $\pm 0,06$. Hasil estimasi korelasi genetik ini lebih besar dibandingkan dengan pernyataan Kiriro (1982) yaitu sebesar 0,54; dan Assan et al. (2002) sebesar 0,18. Perbedaan nilai korelasi genetik antara berat lahir dengan berat sapih dalam penelitian ini diduga karena disamping ternak yang digunakan berbeda juga jumlah sampel yang digunakan berbeda, serta keragaman yang disebabkan oleh lingkungan yang berbeda. Besarnya korelasi genetik ada kaitannya juga dengan frekuensi gen. Besarnya korelasi genetik tergantung pada frekuensi gen sehingga apabila terjadi perubahan frekuensi gen maka korelasi genetik akan berubah. Salah satu faktor yang dapat mengubah frekuensi gen adalah seleksi (Hardjosubroto, 1994).

Seleksi akan menyebabkan frekuensi gen yang homosigot dominan meningkat yang menyebabkan turunnya keragaman genetik. Korelasi genetik dapat berubah dalam populasi yang sama selama beberapa generasi apabila ada seleksi yang intensif untuk satu atau beberapa sifat. Kemungkinan sebab perubahan ini adalah bahwa dalam seleksi gen-gen yang pengaruh pleotropik positif frekuensinya meningkat atau tetap, akibatnya hanya gen-gen dengan pengaruh pleotropik negatif yang mengalami segresi (Jan, 2000).

Cempe dengan berat lahir yang tinggi menunjukkan berat sapih yang tinggi pula. Bila koefisien korelasi antara dua sifat termasuk kategori tinggi dan bernilai positif, maka hanya perlu melakukan seleksi sifat kedua, artinya seleksi untuk meningkatkan prestasi (produktivitas) sifat yang pertama akan diikuti oleh peningkatan prestasi pada sifat kedua (Kurnianto, 2009). Berat lahir mem- punyai korelasi positif terhadap kesukaran melahirkan sehingga sekarang jarang digunakan sebagai kriteria seleksi (Hardjosubroto, 1994).

Hasil perhitungan salah baku untuk korelasi genetik diperoleh sebesar 0,06 jauh lebih kecil dibandingkan dengan salah baku pada heritabilitas yaitu sebesar 0,2 untuk berat lahir dan 0,31 untuk berat sapih. Hal ini tidak sesuai dengan pendapat Warwick et al. (1990) bahwa salah baku korelasi genetik relatif jauh lebih besar daripada salah baku dari taksiran heritabilitas. Perbedaan hasil salah baku tersebut diduga disebabkan oleh tingginya keragaman lingkungan yang tidak terkontrol yang terlibat dalam estimasi walaupun data yang dianalisis sudah dikoreksi terhadap faktor lingkungan yaitu berat lahir dan berat sapih dikoreksi dengan faktor jenis kelamin dan umur sapih.

Korelasi genetik yang diestimasi dengan metode korelasi saudara tiri sebapak, berdasarkan salah bakunya menunjukkan nilai yang rendah. Salah baku estimasi koreasi genetik yang rendah menunjukkan bias yang rendah sehingga baik untuk digunakan dalam program pemuliaan. Tinggi rendahnya salah baku korelasi genetik disebabkan oleh perbedaan jumlah data yang digunakan (Becker, 1992).

Hasil perhitungan korelasi genetik dapat digunakan untuk memperkirakan perubahan pada generasi berikutnya apabila digunakan sebagai salah satu kriteria seleksi. Seleksi yang dilakukan terhadap salah satu dari sifat yang berkorelasi secara genetik akan memberikan respon secara tidak langsung pada sifat lainnya (Jan, 2000). Oleh karena itu, berdasarkan nilai korelasi genetik yang diperoleh pada penelitian ini maka apabila dilakukan seleksi pada berat lahir akan dapat memperkirakan perubahan yang terjadi pada berat sapih. Namun demikian, tidak disarankan sifat berat lahir digunakan sebagai salah satu kriteria seleksi sebab akan mengakibatkan kesulitan kelahiran pada keturunannya.

\section{Kesimpulan dan Saran}

\section{Kesimpulan}

Domba Ekor Gemuk di Unit Pelaksana Teknis Pembibitan Ternak dan Hijauan Makanan Ternak Garahan mempunyai nilai korelasi genetik antara berat lahir dan berat sapih positif tinggi yaitu sebesar 0,82 $\pm 0,06$.

\section{Saran}

Penelitian ini mempunyai kelemahan yaitu data yang digunakan hanya 120 ekor, padahal untuk diperoleh hasil yang lebih bagus diperlukan data minimal 500 ekor, sehingga populasi perlu ditingkatkan. Berat lahir berkorelasi positif dengan 
kesukaran melahirkan sehingga berat lahir tidak perlu ditingkatkan, yang perlu ditingkatkan adalah berat sapih. Ternak yang dijadikan sebagai bibit dipilih yang lahir kembar 2, karena kelahiran tunggal kebanyakan induk beranak pertama dan belum dewasa tubuh sehingga cempe yang dilahirkan akan sulit beradaptasi dan menyebabkan kematian, sedangkan kembar 3 tidak dijadikan bibit karena akan terjadi kompetisi dalam memperoleh susu induk sehingga mortalitasnya tinggi.

\section{Daftar Pustaka}

Assan, N., S. Makuzo, F. Mhlanga and O. Mobuku. 2002. Genetic evaluation and selection response of birth weight and weaning weight in indigenous Sabi sheep. Available at http://www.ajas.info/editor/manuscript/

upload/15_268.pdf. Accession date: December 20, 2013.

Basuki, P., N. Ngadiyono, dan G. Murdjito. 1998. Dasar Ilmu Potong dan Kerja. Laboratorium Ternak Potong dan Kerja. Fakultas Peternakan, Universitas Gadjah Mada. Yogyakarta.

Becker, A. W. 1992. Manual of Quantitative Genetics $5^{\text {th }}$ ed. Academic Enterprises, Pullman. Washington.

Hafez, E. S. E. 1980. Hormones growth factors and reproduction. In: Reproduction in Farm Animal. E. S. E. Hafez (ed). $2^{\text {nd }}$ ed. Lea and Febiger. Philadelphia. pp: 59-80.

Hardjosubroto, W. 1994. Aplikasi Pemuliabiakan Ternak di Lapangan. PT Gramedia Widiasarana Indonesia. Jakarta.

Kurnianto, E. 2009. Pemuliaan Ternak. Graha Ilmu. Yogyakarta.

Kiriro, P. M. 1982. Estimate of genetic and phenotypic parameters for the Dorper, Red Maasai and their crosses. Available at http://www.fao.org/wairdocs/ilri/x5472b/x54 72b19.htm. Accession date: December 20, 2013.
Jan, R. 2000. Penampilan sapi Bali di wilayah proyek pembibitan dan pengembangan sapi Bali di Daerah Tingkat I Bali. Tesis Pascasarjana. Universitas Gadjah Mada. Yogyakarta.

Lasley, J. F. 1978. Genetics of Livestock Improvement. $3^{\text {rd }}$ ed. Prentice-Hall Inc., Eaglewood Cliff. New Jersey.

Mulyanto dan Sarwono. 2004. Beternak Domba. Penebar Swadaya. Jakarta.

Prabawa, D. 2003. Estimasi korelasi genetik dan korelasi fenotip berat lahir dengan berat sapih pada domba Ekor Gemuk di Balai Pembibitan Ternak Garahan Jember Jawa Timur. Skripsi. Fakultas Peternakan, Universitas Gadjah Mada. Yogyakarta.

Sodiq, A. S. A. and E. S. Abidin. 2002. Doe productivity of Kacang Peranakan Etawah goats in Indonesia and factors affecting them. J. Anim. Sci. 72: 1184-1190.

Subandriyo. 1996. Ettawa Grade Goat Production of West Java. Balai Penelitian Ternak Pusat dan Pengembangan Peternakan. Bogor.

Sulastri. 2001. Estimasi parameter genetik sifat-sifat pertumbuhan dan hubungan antara sifat-sifat kualitatif dengan kuantitatif pada kambing Peranakan Ettawa di Unit Pelaksana Teknis Ternak Singosari, Malang, Jawa Timur. Tesis. Universitas Gadjah Mada. Yogyakarta.

Triwulaningsih. 1986. Performa dan evaluasi genetik berat lahir dan berat sapih domba Ekor Gemuk. Tesis. Fakultas Peternakan Institut Pertanian Bogor. Bogor.

Warwick, E. J., J. M. Astuti, dan W. Hardjosubroto. 1990. Pemuliaan Ternak. Gadjah Mada University Press. Yogyakarta. 


\title{
PENGARUH KAYU MANIS (Cinnamomum burmanni Ness ex BI.) SEBAGAI SUMBER SINAMALDEHID TERHADAP PARAMETER FERMENTASI DAN AKTIVITAS MIKROBIA RUMEN SECARA IN VTTRO
}

\author{
THE EFFECT OF CINNAMON (Cinnamomum burmanni Ness eX Bl.) AS SOURCE OF \\ CINNAMALDEHYDE IN THE DIET ON IN VITRO RUMEN FERMENTATION PARAMETERS \\ AND MICROBLAL ACTIVITIES
}

\author{
Harwanto*, Lies Mira Yusiati, dan Ristianto Utomo \\ Fakultas Peternakan, Universitas Gadjah Mada, J1. Fauna No. 3, Bulaksumur, Yogyakarta, 55281
}

\section{INTISARI}

Penelitian ini bertujuan untuk mengkaji pengaruh kayu manis (Cinnamomum burmanni Ness ex Bl.) sebagai sumber sinamaldehid terhadap parameter fermentasi dan aktivitas mikrobia rumen secara in vitro produksi gas selama 72 jam. Perlakuan dibagi empat kelompok yang terdiri dari perlakuan tanpa penambahan sinamaldehid (kontrol) dan penambahan sinamaldehid masing-masing sebesar 200,400 , dan $600 \mathrm{mg} / \mathrm{kg}$ bahan kering (BK) atau setara penambahan serbuk kayu manis sebanyak 15, 30, dan $45 \mathrm{~g} / \mathrm{kg}$ BK pada pakan dengan komponen rumput raja : konsentrat (65:35). Hasil penelitian menunjukkan bahwa penambahan sinamaldehid hingga level $600 \mathrm{mg} / \mathrm{kg} \mathrm{BK}$ tidak berpengaruh terhadap produksi gas metan, total volatile fatty acids, $\mathrm{pH}$, kecernaan bahan kering, kecernaan bahan organik, dan aktivitas mikrobia rumen. Penambahan sinamaldehid level 200, 400, dan $600 \mathrm{mg} / \mathrm{kg}$ BK menurunkan ketersediaan amonia secara linear $(\mathrm{P}<0,05)$ dari 25,85 menjadi 22,97; 22,46; dan $19,91 \mathrm{mg} / 100 \mathrm{ml}$. Berdasarkan hasil penelitian disimpulkan bahwa penambahan sinamaldehid level $200 \mathrm{mg} / \mathrm{kg}$ BK atau setara dengan penambahan serbuk kayu manis sebanyak $15 \mathrm{~g} / \mathrm{kg}$ BK pakan menurunkan amonia secara in vitro.

(Kata kunci: Kayu manis, Sinamaldehid, Parameter fermentasi, Aktivitas mikrobia rumen, In vitro)

\section{ABSTRACT}

This research was aimed to observe the effect of cinnamon (Cinnamomum burmanni Ness ex B1.) as a source of cinnamaldehyde in diet on fermentation parameters and ruminal microbial activities by using in vitro gas production for 72 hours. The treatments were randomly divided into four groups, consisted of the diet without cinnamaldehyde (control) and the diet with 200, 400 and $600 \mathrm{mg}$ cinnamaldehyde addition per $\mathrm{kg} \mathrm{DM}$ feed (65\% king grass and 35\% concentrate) or equivalent to cinnamon powder as much as 15,30 and $45 \mathrm{~g} / \mathrm{kg} \mathrm{DM}$. The results showed that the cinnamaldehyde addition of $600 \mathrm{mg} / \mathrm{kg} \mathrm{DM}$ level did not affect methane gas production, volatile fatty acids, $\mathrm{pH}$, dry matter digestibility, organic matter digestibility and ruminal microbes activities. However, the cinnamaldehyde addition of 200,400 and $600 \mathrm{mg} / \mathrm{kg}$ reduced ammonia level liniarly $(P<0.05)$ from 25.85 to $22.97 ; 22.46$ and $19.91 \mathrm{mg} / 100 \mathrm{ml}$. It can be concluded that the cinnamaldehyde addition of $200 \mathrm{mg} / \mathrm{kg}$ DM or equivalent to $15 \mathrm{~g} / \mathrm{kg}$ DM cinnamon powder decreased in vitro ruminal ammonia concentration.

(Key words: Cinnamon, Cinnamaldehyde, Fermentation parameters, Ruminal microbial activities, In vitro)

\section{Pendahuluan}

Gas metan $\left(\mathrm{CH}_{4}\right)$ merupakan salah satu gas yang menyebabkan terjadinya pemanasan global melalui mekanisme efek rumah kaca. Gas metan berdampak merugikan jika berada di udara bebas karena berinteraksi dengan lapisan ozon dan menyerap sinar inframerah yang melewati atmosfer sehingga menyebabkan terjadinya peningkatan temperatur di permukaan bumi. Metan menyebabkan pemanasan global 21 kali lebih besar daripada $\mathrm{CO}_{2}$ (Mitloehner, 2005). Peternakan berkontribusi $16-20 \%$ dalam pemanasan global dari metan yang dihasilkan. Metan merupakan gas produk fermentasi bahan pakan oleh mikrobia rumen. Fermentasi di dalam rumen, $2-12 \%$ total energi pakan akan dikonversi menjadi metan sehingga menurunkan efisiensi penggunaan bahan pakan (Johnson dan Johnson, 1995).

Pengurangan produksi metan dapat meningkatkan suplai energi sehingga dapat meningkatkan efisiensi penggunaan bahan pakan. Saat ini telah banyak dilakukan usaha untuk memanipulasi proses fermentasi di dalam rumen yang bertujuan mengurangi produksi gas metan. Manipulasi

\footnotetext{
* Korespondensi (corresponding author):

Telp. +6285743017830

E-mail: harwanto_fapetugm@yahoo.co.id
} 